\title{
Influence of operating conditions on the electrolytic treatment for the removal of color, TSS, hardness and alkalinity using Al-Al electrode combination
}

\section{Arun Kumar Sharma* and A. K. Chopra}

Department of Zoology and Environmental Sciences, Gurukula Kangri University, Haridwar-249404 (Uttarakhand), INDIA

*Corresponding author. E-mail: asharma.env@gmail.com

Received: April 20, 2014; Revised received: May 22, 2014; Accepted: June 5, 2014

\begin{abstract}
The present investigation observed the effect of current density (CD), operating time (OT), inter electrode distance (IED), electrode area (EA), initial $\mathrm{pH}$ and settling time (ST) using Al-Al electrode combination on the removal of color, total suspended solids (TSS), hardness (HR) and alkalinity (ALK) from biologically treated municipal wastewater (BTMW) of Sewage Treatment Plant (STP), Jagjeetpur, Haridwar, India. The maximum removal of color $(99.86 \%)$, TSS $(98.7 \%)$, HR $(78.9 \%)$ and ALK $(43.69 \%)$ from BTMW was found with the optimum operating conditions of CD $\left(2.65 \mathrm{~A} / \mathrm{m}^{2}\right)$, OT (40 mins.), IED $(0.5 \mathrm{~cm}), \mathrm{EA}\left(160 \mathrm{~cm}^{2}\right)$, initial pH (7.5) and ST (60 min.). However, the maximum removal of ALK was found with the optimum operating conditions of CD $\left(1.68 \mathrm{~A} / \mathrm{m}^{2}\right)$, OT (40 mins.), IED $(1.0 \mathrm{~cm})$, EA $\left(80 \mathrm{~cm}^{2}\right)$, initial $\mathrm{pH}(7.5)$ and ST $(90 \mathrm{~min}$.) The electrolytic treatment (ET) brought down the concentration of HR and ALK to the desirable limit of the BIS standards of drinking water. There was no need of $\mathrm{pH}$ adjustment of the BTMW during ET as the optimal removal efficiency was close to the $\mathrm{pH}$ of 7.5. Under optimal operating conditions, the operating cost was found to be $1.01 \$ / \mathrm{m}^{3}$ in terms of the electrode consumption $\left(23.71 \times 10^{-5} \mathrm{~kg} \mathrm{Al} / \mathrm{m}^{3}\right)$ and energy consumption $\left(101.76 \mathrm{Kwh} / \mathrm{m}^{3}\right)$. The study revealed that BTMW can be effectively treated with the AI-Al electrode combination for color, TSS, HR and ALK removal.
\end{abstract}

Keywords: Al-Al Electrode combinations, Electrolytic treatment, Operating conditions, Removal efficiency

\section{INTRODUCTION}

Water is an essential substance for living system as it allows the transport of nutrients as well as waste products in the living systems. However, sustainable water supply is becoming more challenging by the day due to ever increasing demand of growing population as well as increasing contamination of water resources. At the same time huge quantities of wastewater generated by industries of every hue and kind and also by exponential growth in the number of households are becoming a serious concern for society (Chopra and Sharma, 2013). Sewage treatment consists of an item that deserves ample documentation due to the environmental impact caused by such wastewater if directly discharged into water bodies. In addition, due to an increase in the scarcity of clean water Aiyuk et al. (2006), there is need for proper management of available water resources. Some of the goals of environmental protection and resource conservation concepts are the re-use of treated wastewater, residues emanating there from and other treatment by-products (Lettinga et al., 2001 and Yi 2001).

Biological processes are the most common methods which are usually employed for the treatment of municipal wastewater (Iniesta et al., 2002). However, due to the long detention time and large treatment system, it results in higher treatment cost. Due to this reason, location of biological treatment utilities has become a big problem in the areas, where there is a scarcity of land and has high land value. In addition to that, biological processes are also susceptible to the changes of influent characteristics and require highly skilled labor. Therefore, there is a need for new and novel processes that could efficiently treat municipal wastewaters at relatively low operating cost. Research shows that electrochemical (EC) processes have the potential to be developed as a robust process, which can completely convert organic pollutants into gases such as $\mathrm{N}_{2}$ and $\mathrm{CO}_{2}$ (Feng et al., 2003).

The role of electrochemistry in water and effluent treatment is relatively small since conventional electrode materials achieve only low current efficiencies due to the water electrolysis side reactions [Comninellis, 1994 and Simonsson, 1997). Matteson et al. (1995) described a device, referred to as an "electronic coagulator" which electrochemically dissolves $\mathrm{Al}$ (from the anode) into the solution, reacting this with the $\mathrm{OH}^{-}$ion (from the cathode) to form aluminum hydroxide. However, the use of sacrificial electrodes of metals which can give rise to multiple charged ions and their corresponding salts in the electrolytic systems, resulting in coagulation and flocculation of dissolved and undisclosed water 
Table 1. Characteristics of BTMW (Values are Mean \pm SD of 5 replicates).

\begin{tabular}{ll}
\hline Parameter & Mean \pm S.D \\
\hline $\mathrm{pH}$ & $7.40 \pm 0.17$ \\
Conductivity $(\mu \mathrm{S})$ & $727.8 \pm 23.05$ \\
TDS $(\mathrm{mg} / \mathrm{l})$ & $472.5 \pm 24.66$ \\
Colour & $92.34 \pm 11.56$ \\
TSS $(\mathrm{mg} / \mathrm{l})$ & $225.34 \pm 15.47$ \\
Hardness $(\mathrm{mg} / \mathrm{l})$ & $336.78 \pm 21.45$ \\
Alkalinity $(\mathrm{mg} / \mathrm{l})$ & $295.5 \pm 11.45$ \\
\hline
\end{tabular}

impurities. This helps in the removal of contaminants from wastewater. In the electrolytic process for the treatment of biologically treated municipal wastewater (BTMW), Al electrodes are dissolved during treatment and form their hydroxides and poly hydroxides which combine and subvert the organic and inorganic impurities in BTMW.

In an electrolytic reactor, generated $\mathrm{Al}^{3+}$ ions immediately hydrolyze to produce corresponding hydroxides and/or poly hydroxides in adequate $\mathrm{pH}$. The Al hydroxides and poly hydroxides from the electrochemical dissolution have been reported to have stronger affinity to capture the pollutants in the wastewater, causing more coagulation than those from the conventional Al coagulants. Although the $\mathrm{Al}(\mathrm{OH})_{3}$ produced by the anodic $\mathrm{Al}$ dissolution is more active to coagulate the pollutants in wastewater, the passivation of $\mathrm{Al}$ anodes and impermeable film formed on cathodes may interfere with the performance of electrocoagulation and electro flotation (Holt et al., 2005). The destabilized particles are believed to be responsible for the aggregation and precipitation of the suspended particles and for the adsorption of the dissolved and/or colloidal pollutants which are subsequently removed by sedimentation and/or flotation (Bayramoglu et al., 2004). The present study was focused to find out the treatability of BTMW in terms of color, TSS, HR and ALK removal by electro- lytic treatment (ET) at various operating conditions using $\mathrm{Al}$ electrodes and also to assess the electrode and energy consumption during the ET.

\section{MATERIALS AND METHODS}

Collection of wastewater samples: The samples of BTMW were collected from the outlet of activated sludge process (ASP) of the sewage treatment plant (STP), Jagjeetpur, Haridwar (Uttarakhand), India and brought to the laboratory and then used for ET using Al-Al electrode combination. The pH of BTMW was adjusted before the electrochemical process and was maintained by adding the required amount of $\mathrm{H}_{2} \mathrm{SO}_{4}$ (1M) or $\mathrm{NaOH}(1 \mathrm{M})$. The characteristics of BTMW are given in table 1.

Electrolytic experimental set up: A rectangular Reactor with external dimensions of height $=30 \mathrm{~cm}$, width $=7 \mathrm{~cm}$, length $=11 \mathrm{~cm}$ and wall thickness $=10$ $\mathrm{mm}$ constructed with glass with a capacity of 2.0 liters sample was used. Each time, the BTMW sample of 2.0 liters was collected and placed in an electrolytic Reactor. Al-Al electrode combination was connected to their respective anode and cathode leading to the D.C. Power supply (LMC electronics, India $0-500 \mathrm{~V}$ and $0-2$ A) and energized for a required duration of time at different voltages and currents. All the experiments were performed at room temperature $\left(30 \pm 2^{\circ} \mathrm{C}\right)$ and at a constant stirring speed $(100 \mathrm{rpm})$ to maintain the uniform mixing of BTMW sample during the ET. Before conducting an experiment, the electrodes were washed with water, dipped into diluted $\mathrm{HCl}(5 \% \mathrm{v} / \mathrm{v})$ for 5 mins., thoroughly washed with water and then finally rinsed twice with distilled water. Electrodes were dipped into BTMW sample with different surface areas $\left(80 \mathrm{~cm}^{2}, 120 \mathrm{~cm}^{2}\right.$ and $\left.160 \mathrm{~cm}^{2}\right)$ and different electrode distances $(0.5 \mathrm{~cm}, 1.0 \mathrm{~cm}, 1.5$ $\mathrm{cm}, 2.0 \mathrm{~cm}$ and $2.5 \mathrm{~cm}$ ). The different voltages ( 5 to 40 volts) were passed for different operating times (10 -

Table 2. Operating cost $(\mathrm{OC})$ using $\mathrm{Al}-\mathrm{Al}$ electrode combination at different electrode areas (EA) at constant operating conditions (Voltage: $40 \mathrm{~V}$, OT:40 min., IED:0.5 cm,pH:7.5 and ST:30 min.).

\begin{tabular}{llllll}
\hline EA $\left(\mathbf{c m}^{2}\right)$ & \multicolumn{5}{c}{ Al-Al electrode combination } \\
\cline { 2 - 6 } & $\mathbf{C D}\left(\mathbf{A} / \mathbf{m}^{2}\right)$ & Final $\mathbf{~ p H}$ & $\mathbf{C}_{\text {electrode }}\left(\mathbf{k g} / \mathbf{m}^{\mathbf{3}}\right)$ & $\mathbf{C}_{\text {energy }}\left(\mathbf{k W h} / \mathbf{m}^{\mathbf{3}}\right)$ & Total OC $\left.(\mathbf{\text { \$./m }})^{\mathbf{3}}\right)$ \\
\hline 80 & 1.68 & 9.21 & $14.99 \times 10^{-5}$ & 64.32 & 0.64 \\
120 & 2.09 & 10.89 & $18.68 \times 10^{-5}$ & 80.16 & 0.80 \\
160 & 2.65 & 11.23 & $23.71 \times 10^{-5}$ & 101.76 & 1.01 \\
\hline
\end{tabular}

Table 3. Rate constant $\left(\mathrm{k}(\mathrm{min}-1)\right.$ values at variable current density and their correlation coefficients $\left(\mathrm{r}^{2}\right)$ using $\mathrm{Al}-\mathrm{Al}$ electrode combination.

\begin{tabular}{|c|c|c|c|c|c|c|c|c|}
\hline \multirow[t]{2}{*}{ Voltage (V) } & \multicolumn{2}{|c|}{ Color } & \multicolumn{2}{|c|}{ TSS } & \multicolumn{2}{|c|}{ HR } & \multicolumn{2}{|c|}{ ALK } \\
\hline & $\mathrm{K}\left(\mathrm{min}^{-1}\right)$ & $\mathbf{r}^{2}$ & $\mathrm{~K}\left(\min ^{-1}\right)$ & $\mathbf{r}^{2}$ & $\mathrm{~K}\left(\mathrm{~min}^{-1}\right)$ & $\mathbf{r}^{2}$ & $\mathrm{~K}\left(\mathrm{~min}^{-1}\right)$ & $\mathbf{r}^{2}$ \\
\hline 5 & 0.0045 & 0.9860 & 0.0018 & 0.9057 & 0.0012 & 0.9066 & 0.0006 & 0.7989 \\
\hline 10 & 0.0083 & 0.9952 & 0.0053 & 0.9933 & 0.0018 & 0.9151 & 0.0020 & 0.9529 \\
\hline 15 & 0.0120 & 0.9959 & 0.0080 & 0.9903 & 0.0029 & 0.9149 & 0.0026 & 0.9770 \\
\hline 20 & 0.0135 & 0.9899 & 0.0094 & 0.9850 & 0.0039 & 0.9360 & 0.0034 & 0.9779 \\
\hline 25 & 0.0157 & 0.9832 & 0.0103 & 0.9770 & 0.0058 & 0.9413 & 0.0042 & 0.9727 \\
\hline 30 & 0.0174 & 0.9785 & 0.0130 & 0.9919 & 0.0075 & 0.9548 & 0.0053 & 0.9888 \\
\hline 35 & 0.0203 & 0.9849 & 0.0148 & 0.9898 & 0.0099 & 0.9823 & 0.0056 & 0.9788 \\
\hline 40 & 0.0217 & 0.9848 & 0.0217 & 0.9981 & 0.0119 & 0.9931 & 0.0062 & 0.9763 \\
\hline
\end{tabular}


$80 \mathrm{~min}$ ). After passing the particular voltage for a particular time period i.e. after each batch experiment, the sample was taken for the different settling times (30, 60 and 90 mins.) as stated earlier (Chopra and Sharma, 2012).

Analytical methods: The color, TSS, HR and ALK of wastewater were analyzed before and after the ET following the standard methods for examination of water and wastewater (APHA,2005). The calculation of color, TSS, HR and ALK of removal efficiencies after ET was carried out using the formula:

$$
\mathrm{CR} \%=\frac{\mathrm{Co}-\mathrm{C}}{\mathrm{Co}} \times 100
$$

Where, $\mathrm{C}_{0}$ and $\mathrm{C}$ are concentrations of wastewater before and after electrolysis.

Kinetic study: The rate of removal of color, TSS, HR and ALK are represented by the following first-order mechanism (Ashtoukhy and Amin, 2010).

$$
\ln \left(\frac{C_{0}}{C_{t}}\right)=k t
$$

Where, $\mathrm{C}_{0}$ - initial concentration $(\mathrm{mg} / \mathrm{L}), \mathrm{C}_{\mathrm{t}}$ - final concentration with respect to time, and $\mathrm{t}$ - the time (min) and $\mathrm{k}$ - the rate constant $\left(\mathrm{min}^{-1}\right)$ for color, TSS, $\mathrm{HR}$ and ALK for ET using Al- Al electrode combination .

\section{RESULTS AND DISCUSSION}

The results on color, TSS, HR and ALK removal efficiency of BTMW by ET at different operating conditions like voltage/current density (CD), operating time (OT), inter electrode distance (IED), electrode area (EA), $\mathrm{pH}$ and settling time (ST) are shown in figs. 1- 6 .

Effect of current density (CD): The effect of CD on the removal percentage of color, TSS, HR and ALK increased progressively with an increase in the CD from 0.16 to $1.68 \mathrm{~A} / \mathrm{m}^{2}$ corresponding to its constant voltages ( 5 to $40 \mathrm{~V}$ ). As indicated in Fig. 1, the maximum removal of color $(82.54 \%)$, TSS $(76.76 \%)$, HR $(59.7 \%)$ and ALK (40.28\%) was with the operating conditions of OT $30 \mathrm{~min}$., IED $1.0 \mathrm{~cm}$, EA $80 \mathrm{~cm}^{2}, \mathrm{pH}$ 7.5 and ST $30 \mathrm{~min}$. This is ascribed to the fact that as the current increased, more amount of $\mathrm{Al}(\mathrm{OH})_{3}$ was produced, which could have contributed for the removal of color, TSS, HR and ALK from BTMW by precipitation and flotation.

The present finding is in support of Bukhari (2008) who stated that $0.05 \mathrm{~A}$ and $0.1 \mathrm{~A}$ of current applied for 5 mins. of electrolytic time resulted in $40-50 \%$ and 50 $-60 \%$ of suspended solids removal efficiency respectively and that the removal efficiency was obtained in proportion to the amount of dissolved materials against each of the working times ranging between 10 and 50 mins. Golder et al. (2007) investigated that more bubbles are generated at higher current and this improves the degree of mixing of $\mathrm{Al}$
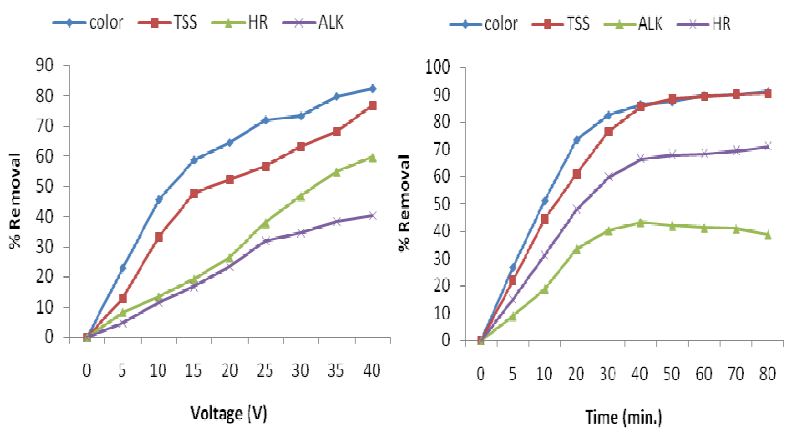

Fig. 1. \% removal of color, Fig. 2. \% removal of color, TSS, HR and ALK using Al- TSS, HR and ALK using AlAl electrode combination Al electrode combination with with different voltages at different OT at constant operconstant operating condi- ating conditions (Volt: 40, tions (OT: 30 min., IED: IED: $1.0 \mathrm{~cm}, E A: 80 \mathrm{~cm}^{2}, \mathrm{pH}$ : $\left.1.0 \mathrm{~cm}, E A: 80 \mathrm{~cm}^{2}, \mathrm{pH}: 7.5,7.5, S T: 30 \mathrm{~min}.\right)$.

ST: $30 \mathrm{~min}$.$) .$
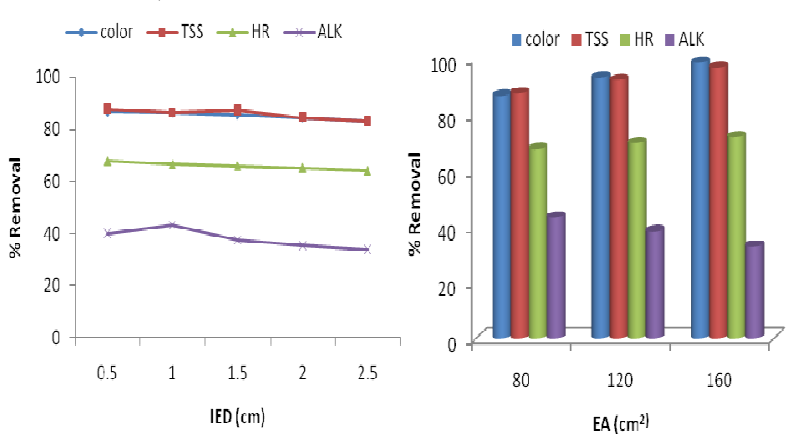

Fig.3. \% removal of color, Fig. 4. \% removal of color, TSS, HR and ALK using Al- TSS, HR and ALK using AlAl electrode combination with $A l$ electrode combination different IED at constant with different EA at constant operating conditions operating conditions (Volt: 40 (Volt:40 , OT: 40 mins., EA: V, OT: 40 mins., IED: 0.5 $80 \mathrm{~cm}^{2}, \mathrm{pH}$ : 7.5, ST:30 min.). $\quad$ cm, pH: 7.5, ST:30 min.).

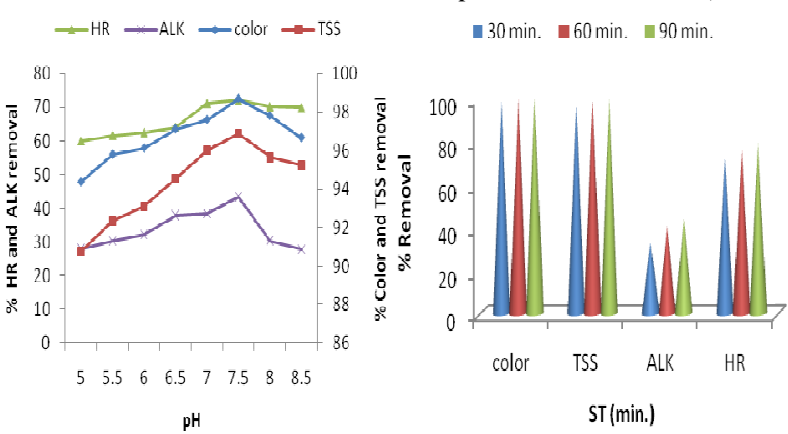

Fig. 5. \% removal of color, Fig. 6. \% removal of color, TSS, $H R$ and ALK using Al- TSS, HR and ALK using Al$A l$ electrode combination Al electrode combination with with different $\mathrm{pH}$ at constant different $S T$ at constant operoperating conditions (Volt: ating conditions (Volt: $40 \mathrm{~V}$, $40 \mathrm{~V}$, OT: 40 mins., IED: 0.5 OT: 40 mins., IED: $0.5 \mathrm{~cm}$, $\left.\left.\mathrm{cm}, E A: 160 \mathrm{~cm}^{2}, S T: 30 \mathrm{~min}.\right) . \quad E A: 160 \mathrm{~cm}^{2}, p H: 7.5\right)$.

$(\mathrm{OH})_{3}$ and phenol which enhances floatation ability of the cell with a consequent increase in the phenol removal efficiency. Moreover, as shown by Khemis et al. (2006), higher production rates of hydrogen allowed by higher currents, favor the flotation of the flocculated matter. Zaroual et al. (2006) investigated that the efficiency of COD removal of textile effluent 
depended on the quantity of hydroxide flocs, which was bound with time and cell current of electro coagulation. When one of the two parameters increased, the distribution of the coagulation agent density was more effective. Song et al. (2008) established that the rate of bubble-generation increases and the bubble size decreases with an increase in CD. Both of these trends are beneficial in terms of high pollutant removal efficiency by $\mathrm{H}_{2}$ floatation.

Effect of operating time (OT): In the present study, OT also influenced the treatment efficiency of ET. With an increase in OT, the anodic electrode dissolution led to release of metal ions and the cathode released $\mathrm{OH}^{-}$which formed their hydroxides into BTMW. Fig. 2 depicts that the removal of color, TSS, HR and ALK increased progressively with an increase in the OT from 5 to $40 \mathrm{~min}$. with the operating conditions of CD $1.68 \mathrm{~A} / \mathrm{m}^{2}$, IED $1.0 \mathrm{~cm}$, EA $80 \mathrm{~cm}^{2}$, pH 7.5 and ST 30 min.. The maximum removal of color $(86.4 \%)$, TSS (85.6\%), HR (66.5\%) and ALK $(43.33 \%)$ was observed at optimum OT of $40 \mathrm{~min}$. beyond which there was no significant removal. This may be due to the fact that the dissolved metal ions and their hydroxides in the BTMW achieved the saturation stage for the floc formation. However, ALK was found to decrease gradually with an increase in OT up to 80 mins. at the constant operating conditions. It has been observed that as the electrolysis period increases, the concentration of metal ions and their hydroxide flocs increases (Zaroual et al., 2006, Daneshvar et al., 2006 and Daneshvar et al., 2007). Holt et al. (2002) investigated that more electro coagulation time (>30 min) and high voltage result in floatation of particles attached to hydrogen gas bubbles released from the cathode which are important for the turbidity removal. Kobya and Delipinar (2008) reported that an increase in the OT from 10 to $60 \mathrm{~min}$. in the treatment of the Baker's yeast wastewater by electro coagulation resulted in an increase in the removal efficiency of COD, TOC and turbidity. Vijayaraghavan et al. (2008) also observed that an increase in the electrolysis period resulted in a decrease in residual COD and BOD concentrations irrespective of the $\mathrm{CD}$ during the ET of latex wastewater. It was established that the anodic electro dissolution leads to release of coagulating species in the wastewater during electrolysis. Aoudj et al. (2010) observed that anodic electro dissolution led to the release of coagulating species at constant $\mathrm{CD}$ of $2.5 \mathrm{~mA} / \mathrm{cm}^{2}$ and initial $\mathrm{pH}$ of 6 . They found that an increase in the time of electrolysis from 10 to $60 \mathrm{~min}$. yields an increase in the dye removal efficiency from $52.5 \%$ to $98.28 \%$.

Effect of inter electrode distance (IED): During the present study, IED was an effective factor in the ET of BTMW. The removal percentage of color, TSS, HR and ALK increased progressively with decrease in IED from 2.5 to $0.5 \mathrm{~cm}$, whereby it exhibited the maximum removal of color, TSS and HR at a short distance of $0.5 \mathrm{~cm}$ between the electrodes, each with an electrode area of $80 \mathrm{~cm}^{2}$ and with the operating conditions of CD $1.68 \mathrm{~A} / \mathrm{m}^{2}$, OT $40 \mathrm{~min}$, EA $80 \mathrm{~cm}^{2}, \mathrm{pH} 7.5$ and ST 30 min. (Fig. 3). After that, there was not much difference in the removal efficiency of color $(86.9 \%)$, TSS $(87.80 \%)$ and HR $(67.8 \%)$ as the IED increased from 0.5 to $2.5 \mathrm{~cm}$., whereas the ALK $(40.25 \%)$ was decreased due to the increase in amount of $\mathrm{Al}(\mathrm{OH})_{3}$ which enhanced the alkaline character of BTMW. Similar observations have also been reported by Li Xu. (2008) for the removal of COD from tridecane dicarboxylic acid wastewater which decreases with the decrease in distance between electrodes of the same composition. This is because the shorter distance speeds up the anion discharge on the anode and improves the oxidation. It also reduces resistance, electricity consumption and the cost of the wastewater treatment. Ghosh et al. (2008) have also observed that with the increase of IED, the percentage removal of dye products from waste water decreases. At a lower IED, the resistance encountered by the current flowing in the solution medium decreases, thereby, facilitating the EP resulting in enhancement of dye removal.

Effect of electrode area (EA): The greater electrode area increases the rate of flock's formation, which in turn influences the removal efficiency of color, TSS and HR. According to Daneshava et al., (2005), an increase of electrode area causes a corresponding increase of coagulants. The entire effectiveness of the coagulation process depends on the appropriate amount of coagulant. The logistical relationship between electrode geometric area (AG) and $\mathrm{Cu}$ removal efficiency and concluded that an increase in $\mathrm{Cu}$ removal was related to an increase in $\mathrm{AG}$, reaching an optimal value of $35 \mathrm{~cm}^{2}$, with an asymptotic value of near $80 \%$ (Escobara et al., 2006). Chopra and Sharma (2013) observed that with a fourfold increase in the electrode area of Al-Fe from 40 to $160 \mathrm{~cm}^{2}$, the $\mathrm{CD}$ increased from 0.24 to $0.58 \mathrm{~A}$, which resulted in an increase in the removal percentage of TD, COD and BOD. The maximum removal efficiencies of $81.51 \%$ (TD), $74.36 \%$ (COD) and $70.86 \%$ (BOD) of BTMW were achieved with the use of electrode area of 160 $\mathrm{cm}^{2}$ and IED of $2.5 \mathrm{~cm}$.

Similarly in the present study, it was observed that with an increase in EA from 80 to $160 \mathrm{~cm}^{2}$, the CD density increased from 1.68 to $2.65 \mathrm{~A} / \mathrm{m}^{2}$ corresponding to its constant voltage of $40 \mathrm{~V}$ that resulted in an increase in the removal percentage of color, TSS and HR of BTMW. The maximum removal of color (98.7\%), TSS (96.89\%) and HR (72.12\%) was achieved at maximum EA of $160 \mathrm{~cm}^{2}$ with the operating conditions of voltage $40 \mathrm{~V}$, OT $40 \mathrm{~min}$., IED $0.5 \mathrm{~cm}$., initial $\mathrm{pH} 7.5$ and ST $30 \mathrm{~min}$., while the removal of ALK (43.33\%) was with the $80 \mathrm{~cm}^{2}$ (Fig. 4). However, the ALK of BTMW was decreased gradually with an increase of the electrode area of 
$\mathrm{Al}-\mathrm{Al}$ electrode combination due to increase in the formation of $\mathrm{Al}(\mathrm{OH})_{3}$ in the BTMW.

Effect of pH: As pointed out by several authors [Lin and Chen, 1997; Chen et al., 2000; Gurses et al., 2002 and Kobya et al., 2003), pH is an important operating factor influencing the electrocoagulation process. $\mathrm{pH}$ of the medium changes during the process depending on the type of electrode material and the initial $\mathrm{pH}$. Gurses et al. (2002) observed an increase in removal efficiency of colloidal particles in the $\mathrm{pH}$ range of 4-7 that leads to the formation of amorphous hydroxide precipitates and other aluminum hydroxo complexes with hydroxide ions and polymeric species. On the other hand, the electro coagulation process exhibits some buffering capacity, especially in alkaline medium, which prevents large changes in $\mathrm{pH}$ and shows a decrease of the pollutant removal efficiency (Bayramoglu, 2004). The difference between maximum $\mathrm{pH}$ for COD and turbidity can be attributed to the formation of more stable flocs when $\mathrm{pH}$ is about 7, although it does not correspond to the optimum for dye removal (Essadki et al., 2008).

In the present study, the removal efficiency of color, TSS, HR and ALK with the different initial concentrations of $\mathrm{pH}$ 5-8.5 of BTMW and at operating conditions of CD $2.65 \mathrm{~A} / \mathrm{m}^{2}$, OT $40 \mathrm{~min}$., IED $0.5 \mathrm{~cm}$, EA $160 \mathrm{~cm}^{2}$ and ST $30 \mathrm{~min}$. indicated that the maximum removal of color $(98.7 \%)$, TSS(96.89\%), HR $(72.12 \%)$ and $\operatorname{ALK}(43.33 \%)$ was at the initial $\mathrm{pH}$ of 7.5 (Fig. 5). After that the removal efficiency of these parameters decreased gradually with the increase in $\mathrm{pH}$ of more than 7.5 at constant operating conditions using $\mathrm{Al}-\mathrm{Al}$ electrode combination. It was found that the $\mathrm{pH}$ of BTMW did not have significant influence on the removal of color, TSS, HR and ALK.

Effect of settling time (ST): The effect of ST on removal efficiency of the parameters after ET has not been given due consideration so far. There appears to be no work with regard to the ST on the BTMW treatment during electrolysis. During the present study, it was interesting to note that the removal efficiency of color, TSS, HR and ALK with the constant operating conditions of CD $2.65 \mathrm{~A} / \mathrm{m}^{2}$, OT $40 \mathrm{~min}$., EA $160 \mathrm{~cm}^{2}$ and $\mathrm{pH} 7.5$ was improved with an increase of settling time from 30 to 90 mins. of treated BTMW. The maximum removal of color $(99.86 \%)$, TSS $(98.7 \%)$, HR $(75.89 \%)$ and ALK (40.59\%) was found at the ST of $60 \mathrm{~min}$. beyond which there was no significant removal of these parameters (Fig. 6). The present study indicated that the ET of BTMW brought down the concentration of HR from $336.78 \mathrm{mg} / 1$ to $81.19 \mathrm{mg} / \mathrm{l}$ and ALK from $295.5 \mathrm{mg} / \mathrm{l}$ to $175.55 \mathrm{mg} / \mathrm{l}$ i.e. to within desirable limit of BIS (1991) standard of drinking water.

Economic evaluation: Electrical energy and electrode consumption are the important parameters in the economic evaluation of EC process. In EC process, the operating cost includes material mainly electrodes and electrical energy cost as well as labor, maintenance, sludge dewatering and its disposal. In the present study, energy and electrode material costs have been taken into account as major cost items in the calculation of the operating cost (US $\$ / \mathrm{m}^{3}$ ) (Ghosh et al., 2008 and Chopra and Sharma, 2012) as follows:

$$
\text { operating } \cos t=a C_{\text {energy }}+b C_{\text {electrode }}
$$

Where, $\mathrm{C}_{\text {energy }}\left(\mathrm{KWh} / \mathrm{m}^{3}\right)$ and $\mathrm{C}_{\text {electrode }}\left(\mathrm{kg} \mathrm{Al} / \mathrm{m}^{3}\right)$ are the consumption quantities for the color, TSS, HR and ALK removal.

"a" electrical energy price 0.1 US\$/ kWh; "b" electrode material price $3.4 \mathrm{US} \$ / \mathrm{kg}$ for Al electrode. Cost due to electrical energy $\left(\mathrm{KWh} / \mathrm{m}^{3}\right)$ is calculated as:

$$
C_{\text {energy }}=\frac{U \times I \times t_{E C}}{v}
$$

Cost for electrode $\left(\mathrm{Kg} \mathrm{Al} / \mathrm{m}^{3}\right)$ was calculated as follows using the equation:

$$
C_{\text {electrode }}=\frac{I \times t \times M_{w}}{z \times F \times v}
$$

Where, $\mathrm{U}$ - cell voltage (V), I- current (A), $\mathrm{t}_{\mathrm{EC}-}$ - time of electrolysis ( $\mathrm{s}$ ) and $\mathrm{v}$ - volume $\left(\mathrm{m}^{3}\right)$ of STS water, MW - molecular mass of aluminum $(26.98 \mathrm{~g} / \mathrm{mol})$,z- no. of electrons transferred $(\mathrm{z}=3)$ and F-Faraday's constant (96487C/mol) .

The energy consumption increased from $64.32 \mathrm{kwh} /$ $\mathrm{m}^{3}$ to $101.76 \mathrm{kWh} / \mathrm{m}^{3}$ with an increase in EA $(80-160$ $\left.\mathrm{cm}^{2}\right)$ and $\mathrm{CD}\left(1.68\right.$ to $\left.2.65 \mathrm{~A} / \mathrm{m}^{2}\right)$ that resulted in increase of the electrode consumption from $14.985 \times 10^{-}$ ${ }^{5}$ to $23.71 \times 10^{-5} \mathrm{~kg} / \mathrm{m}^{3}$ for the removal of color, TSS, HR and ALK from BTMW during ET .The cost for ET of BTMW was found to be $1.01 \$$ in terms of energy and electrode consumption with the optimum operating conditions of $\mathrm{CD}\left(2.65 \mathrm{~A} / \mathrm{m}^{2}\right), \mathrm{OT}(40 \mathrm{~min}$.), $\operatorname{IED}(0.5$ $\mathrm{cm}), \mathrm{pH}(7.5)$ and ST( $90 \mathrm{~min}$.) of EC process (Table 2).

Kinetic evaluation: In the present study, it was revealed that the slope of the plot of $C_{0} / C_{t}$ versus time gives the value of the rate constant at the various voltages for color, TSS, HR and ALK (Figs. 7 and 10). The study indicated that the pseudo-first-order abatement kinetic was relatively fitted. The increase in the voltages form 5 to $40 \mathrm{~V}$ increased the rate constant from 0.0045 to $0.0217 \mathrm{~min}^{-1}$ (Color), 0.0018 to $0.0217 \mathrm{~min}^{-1}$ (TSS) and 0.0006 to $0.0062 \mathrm{~min}^{-1}$ (ALK) and $0.0012 \mathrm{~min}^{-1}$ to $0.0119 \mathrm{~min}^{-1}$ for the ET of BTMW using Al-Al electrode combination. The increase in the rate constant may be ascribed to the decrease of color, TSS, HR and ALK of the BTMW. The removal of color, TSS, HR and ALK exhibited pseudo first order kinetic with the significant correlation coefficients $(>.79)$ at maximum voltage of $40 \mathrm{~V}$ (Table 3).

\section{Conclusion}

The removal of color, TSS, HR and ALK from BTMW using $\mathrm{Al}$ electrodes was found to be dependent on 
voltage/CD, OT, IED, EA and initial $\mathrm{pH}$ during the ET. The maximum removal of color, TSS and HR was with the optimal operating conditions of CD $2.65 \mathrm{~A} /$ $\mathrm{cm}^{2}$, OT $40 \mathrm{~min}$., EA $160 \mathrm{~cm}^{2}$ and $\mathrm{pH} 7.5$. However, the maximum removal of ALK was found with the optimum operating conditions of CD $\left(1.68 \mathrm{~A} / \mathrm{m}^{2}\right)$, OT (40 mins.), IED $(1.0 \mathrm{~cm})$, EA $\left(80 \mathrm{~cm}^{2}\right)$, initial $\mathrm{pH}$ (7.5) and ST (60 min.) The interesting thing was that there was no need of $\mathrm{pH}$ adjustment of the BTMW during ET as the optimal removal efficiency was close to the $\mathrm{pH}$ of 7.5. The ET brought down the concentration of HR and ALK to the desirable limit of the BIS standards of drinking water. The kinetic rate constants for color, TSS, HR and ALK removal at various voltages indicated that pseudo first-order kinetic were in good agreement with the significant correlation coefficients (>.79) at maximum voltage of $40 \mathrm{~V}$. The operating cost for the ET of BTMW was found to be $1.01 \mathrm{US} \$ / \mathrm{m}^{3}$ in terms of energy and electrode consumption.

\section{ACKNOWLEDGEMENT}

The University Grant Commission, New Delhi, India is acknowledged for providing the financial support in the form of UGC Research Fellowship (F.4-1/2006 (BSR) 7-70/2007 BSR) to Mr. Arun Kumar Sharma.

\section{REFERENCES}

Aiyuk, S., Forrez, I., Kempeneer, D. L., Haandel, A. and Verstraete, W. (2006). Anaerobic and complementary treatment of domestic sewage in regions with hot climates-A review. Bioresource Technology, 97:22252241.

Aoudj, S., Khelifa, A., Drouiche, N., Hecini, M. and Hamitouche, H. (2010). Electrocoagulation process applied to wastewater containing dyes from textile industry. Chem. Eng. Process., 49: 1176-1182.

APHA (2005). Standard methods for the examination of water and wastewater. American Public Health Association, 21st edn. Washington, DC. .

Ashtoukhy, ES.Z.E. and Amin, N.K. (2010). Removal of acid green dye 50 from wastewater by anodic oxidation and electrocoagulation-A comparative study. Journal of Hazardous Materials, 179:113-119.

Bayramoglu, M., Kobya, M., Can, O.T. and Sozbir, M. (2004). Operating costs analysis of electrocoagulation of textile dye wastewater. Sep. Purif. Technol., 37: 117125.

BIS (1991).Specifications for Drinking Water, IS: 10500:1991, Bureau of Indian Standards, New Delhi.

Bukhari, A.A.(2008). Investigation of the electro-coagulation treatment process for the removal of total suspended solids and turbidity from municipal wastewater. Bioresour. Technol., 99:914-921.

Chen, X., Chen, G. and Yue, P. L.(2000). Separation of pollutants from restaurant waste water by electro - coagulation. Separation and purification technology. 19:65-76.

Chopra A. K. and Sharma A. K. (2013). Removal of turbidity, COD and BOD from secondarily treated sewage water by electrolytic treatment. Appl. Water Sci.,
3:125-132.

Chopra, A. K. and Sharma, A. K.(2012). Efficiency of turbidity and BOD removal from secondarily treated sewage by electrochemical treatment. Journal of Applied and Natural Science, 4:304-309.

Comninellis, Ch.(1994). Electrocatalysis in the electrochemical conversion/combustion of organic pollutants for wastewater treatment, Electrochim. Acta, 39:18571862.

Daneshava, N., Oladegaragoze, A. and Djafarzadeh, N. (2005). Decolorization of Basic Dye Solutions by Electrocoagulation: an investigation of the effect of operational parameters, Journal of Hazardous Materials, 129:116-122.

Daneshvar, N., Khataee, A.R., Amani Ghadim, A.R. and Rasoulifard M.H., (2007). Decolorization of C.I. acid yellow 23 solution by electrocoagulation process: investigation of operational parameters and evaluation of specific electrical energy consumption (SEEC), $J$. Hazard. Mater., 148: 566-572.

Daneshvar, N., Oladegaragoze, A. and Djafarzadeh, N., (2006). Decolorization of basic dye solutions by electro coagulation: An investigation of the effect of operational parameters; Journal of Hazardous Materials $B, 129: 116-122$.

Escobara, C., Cesar S.S. and Toral, M. (2006). Optimization of the electrocoagulation process for the removal of copper, lead and cadmium in natural waters and simulated wastewater. J. Environ. Manag., 81(4): 384-391.

Essadki A.H., Bennajah, M., Gourich, B., Vial, C., Azzi, N. and Delmas, H. (2008). Electrocoagulation/ electroflotation in an external-loop airlift reactorApplication to the decolorization of textile dye wastewater A case study. Chem. Eng. Process., 47:12111223.

Feng, C, Sugiura, N., Shimada, S. and Maekawa, T.(2003). Development of a high performance electrochemical wastewater treatment system. J. Hazard. Mater. B, 103 : 65- 78.

Ghosh, D., Medhi, C.R., Solanki, H., and Purkait, M. K., (2008). Decolorization of Crystal Violet Solution by Electrocoagulation. Journal of environmental protection science, 2:25 - 35 .

Golder, A.K., Samanta, A.N., and Ray, S. (2007). Removal of trivalent chromium by electrocoagulation, Sep. Purif. Technol., 53:33-41.

Gurses, A., Yalcin, M., and Dogar, C.(2002). Electro coagulation of some reactive dyes: a statistical investigation of some electrical variables. Waste management, 22:, 491-499.

Holt P.K., Barton, G.W. and Mitchell, C.A. (2005). The Future For: Electrocoagulation as a localized water treatment technology. Chemosphere, 59:355-367

Holt, P. K., Barton, G. W., Wark, M. and Mitchell, C. A. (2002). A quantitative comparison between chemical dosing and electro coagulation; Colloids and Surfaces, 211:233-248.

Iniesta, J., Exposito, E., Gonzalez-Garcia, J., Monitel, V., Aldaz, A.,(2002). Electrochemical Treatment of Industrial Wastewater Containing Phenols. Journal of Electrochemical Society, 149: 57-62.

Khemis, M., Leclerc, J.P., Tanguy, G., Valentin, G. and Lapicque, F., (2006). Treatment of industrial liquid wastes by electro-coagulation: Experimental investiga- 
tions and an overall interpretation model; Chemical engineering science, 61:3602-3609

Kobya, M. and Delipinar, S. (2008). Treatment of the baker's yeast wastewater by electrocoagulation. $J$ Hazard Mater., 154:1133- 1140

Kobya, M., Can, O. T. and Bayramoglu, M.(2003). Treatment of textile waste waters by electro coagulation using iron and aluminum electrodes. Journal of hazardous materials, $B$ 100:163-178.

Lettinga, G., Van Lier, Van, J.B., Buuren, J.C.L. and Zeeman, G.(2001). Sustainable development in pollution control and the role of anaerobic treatment. Water Sci. Technol., 44: 181-188.

Li Xu, Wang Wei, Wang Mingyu, Cai Yongyi (2008). Electrochemical degradation of tridecane dicarboxylic acid wastewater with tantalum-based diamond film electrode. Desalination, 222: 388-393.

Lin, S.H. and Chen, M.L.(1997). Treatment of textile wastewater by electrochemical methods for reuse. Water Res.,31:868-876.

Matteson, M.J., Dobson, R.L., , Glenn, R.W., Kukunoor,
N.S., Waits, W.H. , Clayfield, E.J.(1995). Electro coagulation and separation of aqueous suspensions of ultrafine particles. Colloids Surf. A, 104: 101-109.

Simonsson, D.(1997). Electrochemistry for a cleaner environment. Chem. Soc. Rev., 26: 181-189.

Song, S., Yao, J., He, Z., Qiu, J. and Chen, J. (2008). Effect of operational parameters on the decolorization of C.I. Reactive Blue 19 in aqueous solution by ozoneenhanced electrocoagulation. J. Hazard. Mater., 152: 204-210.

Vijayaraghavan, K., Ahmad, D., Yuzri, A. and Yazid, A. (2008). Electrolytic treatment of latex wastewater. Desalination, 219:214-221

Yi, Q.(2001). A sustainable technology for developing countryanaerobic digestion, In: Proc. 9th World Congress on Anaerobic Digestion-Anaerobic Conversion for Sustainability (Part 1). Antwerp, Belgium, September. 2-6: 23-30.

Zaroual, Z, Azzi, M. and Saib, N. (2006). Contribution to the study of electrocoagulation mechanism in basic textile effluent. J Hazard Mate, 131(1-3):73-78. 